\title{
observador fotográfico em Contemplação, de Franz Kafka
}

\author{
[The photographic observer in Franz Kafka's Meditation] \\ http://dx.doi.org/10.11606/1982-88372444141
}

Juliana Lusão ${ }^{1}$

\begin{abstract}
This essay investigates how photography, a medium that was rapidly developing and expanding in the beginning of the $20^{\text {th }}$ century, is present in the writing of Meditation (1912), by Franz Kafka. Mentioned in other prose texts by the author, photography is actually incorporated in Meditation's writing. The collection of short prose, published in 1912, is mentioned in the author's letters as a trustworthy portrait of himself, more so than photographic images could ever create. Through the close-reading of the fragment "The passenger" and references by Franz Kafka himself in his Correspondence and Diaries, the hypothesis that there is an intimate relationship between the author's writing and the then new medium is developed here.
\end{abstract}

Keywords: Franz Kafka; Meditation; Photography.

Resumo: O presente artigo busca investigar como a fotografia, técnica em expansão no início do século 20, se faz presente na escrita de Contemplação (1912), de Franz Kafka. A técnica se faz presente em outros textos em prosa do autor, mas em Contemplação Kafka incorpora a fotografia à escrita. Em cartas, o autor se refere ao conjunto de prosas curtas publicado em 1912 como um retrato pessoal muito mais fidedigno do que a própria técnica fotográfica seria capaz de produzir. A partir da análise textual da narrativa breve "O passageiro", ao lado das referências de Franz Kafka em seus Diários e Cartas, desenvolve-se aqui a hipótese de que há uma íntima relação da escrita do autor com a nova técnica de então.

Palavras-chave: Franz Kafka; Contemplação; Fotografia.

Als dauere die Gegenwart eine Ewigkeit

Siegfried Kracauer, Georg

\section{Publicação}

Em 13 de agosto de 1912, Franz Kafka entregava ao amigo Max Brod um magro envelope com o manuscrito do que seria seu primeiro livro, Contemplação, para que fosse enviado à editora de Ernst Rowohlt e Kurt Wolff. Já em outubro do mesmo ano, o autor receberia

\footnotetext{
${ }^{1}$ Universidade Federal Fluminense, Rua Prof. Marcos Waldemar de Freitas Reis, s/nº, Bloco C, sala 314, Niterói, RJ, 24220-900, Brasil. E-mail: julianalugao@id.uff.br. ORCID: 0000-0001-7942-9405
} 
LUGÃO, J. - O observador fotográfico em Contemplação

as provas do livro, com a publicação já acertada com a casa editorial de Leipzig que visitara no mês de junho daquele mesmo ano, impressionando os dois sócios. ${ }^{2} \mathrm{O}$ livro, dedicado a Brod, foi publicado no fim de 1912, mas com a data de 1913, em uma tiragem de 800 exemplares - e impresso em tipos muito maiores que os convencionais, fazendo com que as 32 páginas que compunham o magro manuscrito chegassem a 99, demonstrando destarte uma preocupação de Kafka com a forma material e visual do livro.

Os dezoito fragmentos que compõem Contemplação não eram totalmente inéditos: como era comum acontecer com muitos autores da época, em especial os mais experimentais, a imprensa seria o primeiro espaço a acolher a escrita de Kafka. Oito dos dezoito fragmentos tiveram sua primeira publicação já em 1908, na revista literária Hyperion, e outros cinco no jornal de Praga, Bohemia, em 1910.

Sem sucesso nas vendas, o livro Contemplação recebeu alguma atenção da crítica. As primeiras resenhas chegaram a comparar o estilo da coletânea com a escrita de Robert Walser e Peter Altenberg, autores já consagrados à época. Otto Pick escreveu que Kafka personificava um novo observador ("neue Art von Betrachter"), que apresentava o mundo como um enigma interminável; Robert Musil escreveu uma resenha apontando semelhanças e diferenças da escrita de Kafka com a escrita de Walser, ressaltando que Kafka demonstrava um enorme controle artístico sobre sua escrita (NEYMEYR 2010: 112).

\section{"Não tenha medo, querida"}

A publicação de Contemplação, na virada de 1912 para 1913, coincide com o período em que Kafka manteve constante correspondência com a noiva Felice Bauer. Na madrugada de 3 para 4 de Janeiro de 1913, o autor encerrava sua carta endereçada à noiva comentando um retrato, que enviava junto, no envelope:

Com o risco de estragar teu domingo, te envio minha mais recente fotografia e mando três exemplares de uma só vez, porque achei que, por ser reproduzida um certo número de vezes, ela perde um pouco de seu lado assustador. Não posso fazer nada por ela, esses instantâneos me dão um ar demente, estou com o rosto inclinado, com os olhos estrábicos e o olhar fixo. Não tenha medo, querida, eu não tenho esta aparência, esta fotografia não

\footnotetext{
${ }^{2}$ Em 1913, Wolff criaria uma editora própria, a KWV [Kurt Wolf Verlag], e continuaria publicando as obras de Kafka. Considerado um visionário, "sismógrafo da modernidade literária", o editor mais tarde seria descrito por Kafka de forma sarcástica como um "jovem extremamente belo, a quem Deus presenteou com uma bela mulher, alguns milhões de Marcos, paixão pelo ofício de editar e pouco tino para o negócio da edição" (ALT 2005: 246s).
} 
LUGÃO, J. - O observador fotográfico em Contemplação

corresponde à realidade, não a leve com você, logo logo eu te enviarei uma melhor. Na realidade eu sou duas vezes mais bonito que nesta fotografia. Se você não se contentar com isso, querida, então certamente será terrível! O que farei? Porém você já tem uma imagem de mim absolutamente conforme a realidade; tal qual você vê no meu pequeno livro [Contemplação], tal qual eu sou na realidade, ou talvez tal qual eu era recentemente. (KAFKA 1985: 241).

Entre as referências a outros aspectos sobre a obra do autor, as Cartas a Felice chamam a atenção pela a recorrência de menções à fotografia - e não se trata aqui da mera troca de retratos entre os namorados. Na correspondência saltam aos olhos reflexões sobre a fotografia ou, ainda, reflexões sobre a linguagem e seus desdobramentos aqui já totalmente permeadas pela técnica, como é o caso do trecho transcrito acima. As considerações do autor tcheco são de tal sensibilidade, que o germanista Gerhard Richter (RICHTER 2007) chega a considerar Kafka "o grande desconhecido teórico da fotografia" por suas reflexões sobre o tema nas cartas.

Também os diários do autor evidenciam a fascinação de Kafka por uma grande variedade de tecnologias e novos meios de representação visual, que ele encontrava tanto em sua Praga natal como em suas viagens - na verdade, o interesse de Kafka pelas novas técnicas de representação aparece já nas entradas de 1910 dos diários, as mais antigas a que se tem acesso. O leitor encontra, ao longo dos diários e anotações de viagem, descrições de diferentes meios, técnicas de representação e efeitos óticos, além de reflexões sobre as relações entre as tecnologias visuais e o texto literário (DUTTLINGER 2007: 33).

Ainda que não pareça produtiva a hipótese de tratar Contemplação como um modo de escrita de si, velado ou não, é incontornável o fato de que Kafka utilizava os espaços da escrita íntima como lugares de reflexão e, ao mesmo tempo, "laboratórios da experimentação" da escrita (ALT 2005: 160). Obra ficcional e escrita íntima, portanto, são interpenetráveis no caso da produção textual de Franz Kafka e é quase impossível tratar criticamente da produção do autor sem recorrer aos seus diários ou cartas - edições críticas especializadas sobre a obra do autor costumam vir permeadas de notas que

\footnotetext{
${ }^{3}$ Para efeito de comparação, o texto original: „Auf die Gefahr hin, Dir den Sonntag zu verderben, schicke ich Dir meine neueste Photographie, und zwar gleich in 3 Exemplaren, da ich gefunden haben glaube, daß sie in größerer Anzahl an Schrecken verliert. Ich weiß mir keine Hilfe, Dieses Blitzlicht gibt mir immer ein irrsinniges Aussehn, das Gesicht wird verdreht, die Augen schielen und starren. Habe keine Angst, Liebste, so sehe ich nicht aus, dieses Bild gilt nicht, das sollst du nicht bei dir tragen, ich werde dir bald ein besseres schicken. In Wirklichkeit bin ich zumindest noch einmal so schön wie auf dem Bild. Genügt Dir das nicht, Liebste, dann ist es allerdings schlimm. Was soll ich dann machen? Übrigens hast Du ja ein ganz wahrheitsgemäßes Bild von mir; so wie ich in dem kleinen Buch [Betrachtung] aussehe, so sehe ich auch wirklich aus, so sah ich wenigstens vor kurzem aus " (cf. KAFKA, 2005: 544).
}

Pandaemonium, São Paulo, v. 24, n. 44, set.-dez. 2021, p. 141-156 
LUGÃO, J. - O observador fotográfico em Contemplação

retomam esses espaços da escrita íntima. E, afinal, é Kafka mesmo quem escreve à noiva que Contemplação seria um melhor retrato de si do que a própria fotografia que enviava.

A passagem retirada das cartas a Felice Bauer trazida acima revela algumas questões essenciais à discussão em torno da fotografia, técnica que tanto abalava os conceitos de percepção na virada do século 19 para o século 20, e que, pouco a pouco, passava a ganhar mais terreno como tema de reflexão. Franz Kafka, na carta, além de deixar transparecer certa vulnerabilidade e insegurança para a noiva, dá especial importância à possibilidade de reprodução da imagem fotográfica (envia três exemplares) e a consequência anestesiante desta reprodutibilidade, sem deixar de lado o estranhamento que causa ser e se ver fotografado (mostrando-se vulnerável) e a frustração que causa a impossibilidade de a fotografia representar a realidade tal como a enxergam os indivíduos. Por último, mas não menos importante, como vimos, o autor descreve Contemplação metaforicamente como um retrato fotográfico, dando ao livro até a dimensão temporal da técnica fotográfica: a capacidade de fixar no tempo uma determinada aparência, fazendo-a atravessar o tempo ("ou tal qual eu era recentemente") poderia ser encontrada na coletânea Contemplação, escreve o autor. Estaria Kafka preocupado com a própria aparência na fotografia ou com a recepção da namorada para o livro que enviara?

A pista para responder a essa pergunta está nas mesmas Cartas a Felice, e, mais uma vez nos levam ao universo das imagens técnicas. De 29 para 30 de dezembro de 1912, apenas três dias antes de dizer que o livrinho seria um retrato seu, Kafka se queixa com a noiva, por ela não ter, aparentemente, apreciado Contemplação, e oferece a própria visão sobre o livro, não sem conceder que também estaria infeliz com o resultado. Como se estivesse em um jogo de toma-lá-dá-cá, Kafka dissimula concordar com as possíveis ressalvas que Felice possa ter ao livro, mas não deixa de defender sua obra: "De fato há nele uma desordem incorrigível, ou mais exatamente instantes de clareza numa confusão infinita, e para se ver alguma coisa é necessário olhá-lo bem de perto" (KAFKA 1985: 227228). ${ }^{4}$ A tradução de Robson Soares de Medeiros, ao eleger “instantes de clareza”, parece

\footnotetext{
${ }^{4}$ „Es ist ja wirklich eine heillose Unordnung darin oder vielmehr: es sind Lichtblicke in eine unendliche Verwirrung hinein und man muß schon sehr nahe herantreten, um etwas zu sehn" (KAFKA 2005: 538). Neste caso, sugiro uma possível alternativa à tradução: Há, sim, uma desordem incorrigível ali, ou mais exatamente: são lampejos que penetram numa confusão infinita, e para se ver algo coisa é preciso olhar bem de perto.
}

Pandaemonium, São Paulo, v. 24, n. 44, set.-dez. 2021, p. 141-156 
LUGÃO, J. - O observador fotográfico em Contemplação

já interpretar o que escrevia Kafka à noiva, em lugar de deixar aparecer a imagem por ele utilizada.

A palavra Lichtblicke, aqui sugerimos lampejo, em caráter provisório (ver nota 3), ao ser traduzida por instantes de clareza, perde a conotação de imagem repentina. Além disso, em língua alemã, Lichtblick remete a Lichtbild, palavra utilizada para designar a fotografia em língua alemã, quando da invenção da técnica e ainda hoje utilizada para nomear o retrato pessoal utilizado em documentos; por último, sonoramente, Lichtblick ainda faz lembrar o Blitzlicht, a luz repentina do flash fotográfico, que, ao iluminar uma cena, a isola do que está em volta.

É importante notar que Kafka vive e escreve na virada do século 19 para o século 20, época que veria, ao lado da crise dos modelos de representação e da arte, a proliferação da imagem fotográfica não apenas nos meios de comunicação impressos, mas também pela produção das câmeras portáteis de valor acessível às famílias, possibilitando o surgimento da figura do fotógrafo amador. ${ }^{5}$ A resposta literária às diversas ramificações estéticas, sociais e culturais da fotografia também não demoraria a aparecer. Se desde a invenção de Daguerre anunciada com entusiasmo por Arago, em 1839, a natureza mecânica do processo de registro e o realismo das imagens resultantes foram vistos como uma ameaça que se impunha às artes visuais (que responderam com movimentos estéticos que buscavam a abstração), a literatura, de início, também não recebeu bem a nova técnica. Carolin Duttlinger, em seu extenso e minucioso estudo sobre a relação entre a obra de Kafka e a fotografia, aponta que autores como Heinrich Heine e Charles Baudelaire perceberiam a fotografia como uma prática diametralmente oposta à da escrita literária, pois, segundo eles, não deixaria qualquer espaço para a criatividade ou intervenção humana. E mesmo os realistas e naturalistas, cuja proposta literária poderia ser vista como um eco do caráter imediato da imagem fotográfica, procuraram se distanciar das cópias da realidade consideradas "mecânicas e sem alma" feitas pela câmera (2007: 9).

Nas primeiras décadas do século 20, a relação de escritores com a fotografia começaria a mudar e surgiriam experimentos como Nadja, de André Breton (1928),

\footnotetext{
${ }^{5}$ Com a popularização das câmeras portáteis, qualquer um poderia registrar a vida fotograficamente e ter a sensação de eternizar alguns momentos. Quanto mais corriqueiro o ato fotográfico, mais esse modo de representação se infiltra nas formas de olhar, pensar, registrar.
} 
LUGÃO, J. - O observador fotográfico em Contemplação

sobretudo no âmbito do Surrealismo. ${ }^{6}$ A integração da fotografia e do texto literário seria desenvolvida ainda pelos movimentos de vanguarda, especialmente o Dadaísmo (com suas colagens). Na Praga de Kafka, por exemplo, um grupo local de artistas liderados por Karel Teige, o Deve`tsil, criaria mais tarde, nos anos 1920, os “poema-imagem”, colagens de texto e fotografia. Centrado inicialmente na poesia, o Deve tsil reuniria artistas de diversas formações como o fotógrafo Jaroslav Rössler e a tradutora de Kafka, Milena Jesenska (DUTTLINGER 2007: 10).

A técnica fotográfica logo seria objeto de análises históricas e sociais e as implicações do seu surgimento e desenvolvimento seriam temas recorrentes nos ensaios críticos do início do século - como os de Siegfried Kracauer (“A fotografia”, 1927) e Walter Benjamin ("Pequena História da Fotografia", 1931).

Kafka estava, portanto, imerso no debate das relações entre a fotografia e a escrita. ${ }^{7}$ Em seu ensaio "Pequena História da Fotografia", Walter Benjamin chama a atenção para um fator importante em torno do surgimento e desenvolvimento da nova técnica: a investigação deveria sair das distinções estéticas e ser transposta para a esfera das funções sociais da fotografia (BENJAMIN 1994: 101-102). De fato a fotografia ainda teria implicações em todas as esferas do modo de vida da população, incluindo pensamento e práticas artísticas. E a palavra imagem (Bild, em alemão), por sua vez, também terá seu campo semântico ampliado. Com a imprensa ilustrada, a fotografia e a gravura passam a ser incluídas no campo semântico da genérica palavra imagem (BRUHN 2008: 118-119).

Não obstante o frisson diante das novas técnicas de reprodução e a mudança nos modos de percepção, a palavra, sobretudo a escrita literária, parece ser mais potentes que a fotografia para Kafka. Ou, ao menos, as palavras parecem dar conta de algo que a fotografia não alcançaria.

\footnotetext{
${ }^{6}$ Não é coincidência que Walter Benjamin escolha a palavra "instantâneo" (Momentaufnahme) para dar título a seu ensaio sobre o movimento, "O surrealismo - o último instantâneo da inteligência europeia" (1929) e, em seu "Pequena História da Fotografia" (1931), se refira à fotografia surrealista como "a vanguarda do único destacamento expressivo que o Surrealismo conseguiu pôr em marcha". Vf. Walter Benjamin, 1994, p. 21 e p. 100, respectivamente.

${ }^{7}$ Sobre a relação entre Kafka e as vanguardas históricas, ver, de Detlev Schöttker (2010), „Vielfältiges Sehen - Franz Kafka und der Kubismus in Prag" [Franz Kafka e o Cubismo em Praga].
} 


\section{Um novo observador: contemplar, escrever}

Otto Pick, ao escrever sua crítica, e partir do título do livro (Betrachtung) para escrever a frase que resumiria sua avaliação de que se tratava de uma nova forma de escrever, um novo observador, (eine neue Art von Betrachter), presenteia o leitor com um caminho para perceber Franz Kafka como aquele que escreve, mas também como aquele que olha.

Os lampejos (Lichtblicke) de que fala Kafka em sua carta, parecem ser a estrutura que permeia, ou serve de base a Contemplação. Se a fotografia parecia ter invadido o pensamento da época e, consequentemente, a escrita, Kafka, autor extremamente conectado com seu tempo, com as vanguardas, não lutaria para resistir à técnica ou simplesmente ignorá-la. Entre as narrativas do autor, não é exclusividade de Contemplação a presença de histórias que aparentam ser fotográficas em sua estrutura e iniciam com um fato supostamente adiantado, como se, em vão, requisitassem informações anteriores, um histórico, uma introdução, um complemento explicativo.

Para fins de ilustração, é possível recorrer a um dos exemplos mais citados da obra do autor: "Quando certa manhã Gregor Samsa acordou de sonhos intranquilos, encontrouse em sua cama metamorfoseado num inseto monstruoso" (KAFKA 1997: 6.). Nessa famosa abertura de A metamorfose (1915), o leitor é posto diante do despertar assustado do personagem Gregor Samsa. Quem é Gregor Samsa? Quando ele foi dormir? São todas perguntas cujas respostas são ignoradas pela narrativa, que apresenta o clímax já na abertura.

Se Contemplação não trata da fotografia como tema, diferentemente de outras narrativas mais longas, ${ }^{8}$ o leitor pode perceber, desde a escolha do título, o fundamento fotográfico dado a essa escrita. Quem contempla é fixado em um presente que parece durar a eternidade. Passa a desconsiderar o passado do objeto contemplado ou a história que o tenha feito alcançar esse agora infinito. Igualmente despreza o futuro daquilo que é contemplado: não projeta transformações, não cria expectativas, percebe o objeto neste exato momento. Contemplar é um modo de observação que depende da suspensão do tempo. A palavra alemã escolhida por Kafka para o título, Betrachtung, traz, de um lado, o sentido concreto da percepção e apreensão ótica do mundo exterior. De outro, traz o sentido da reflexão abstrata ou da interiorização contemplativa - aqui, reflexões sobre o

\footnotetext{
${ }^{8}$ Sobre a relação entre a obra de Kafka como um todo e a fotografia, veja-se Kafka and Photography (2007), de Carolin Duttlinger, já citado aqui. A autora se detém especificamente sobre os Diários, as Cartas a Felice, $O$ desaparecido, A metamorfose, $O$ processo, $O$ castelo e "Um artista da fome".
} 
LUGÃO, J. - O observador fotográfico em Contemplação

ato de olhar (NEYMEYR 2010: 113). Por isso, a tradução Contemplação parece mais apropriada que Meditações, outra tradução do título do livro (na variante de Portugal), realizada pelo poeta Alfredo Margarido. "Contemplação", além de vir no singular, exigência de Kafka para o título do livro no processo de sua publicação, carrega a conotação do olhar, da visualidade, a que a palavra "meditação" não remete de forma imediata.

Diversas narrativas de Contemplação iniciam com frases que se assemelham a comentários ou pontos de vista do narrador, carregados de um tom prosaico que se avizinharia da crônica, não fossem ficção e linguagem em experimento. "Decisões" principia com uma espécie de impressão do narrador, intuindo que mesmo com deliberada energia deve ser fácil levantar-se de um estado miserável. Noutro ponto, o leitor é convidado a ver a força de persuasão do ar depois do temporal. A construção literária pressupõe que o narrador já não recorre à experiência: as ações, as imagens e as coisas são oferecidas ao leitor de modo imediato, aparecem como se fossem parte do fluxo de consciência do narrador, no mesmo tempo e espaço presente em que seus personagens agem. Essa forma de narrar de Kafka, cuja relação com o tempo presente do acontecimento parece indissociável, não dá espaço para antecedentes ou projeções, são instantâneos que abolem as relações de causa e efeito, como se fossem cliques oportunos da câmera.

Ao não interrogarem nem passado nem futuro, narradores e personagens de Contemplação se movimentam no mundo como se fosse eterna a duração do que ali se passa. Como se o presente durasse uma eternidade, assim como um flagrante fotográfico. Ocorre uma adesão ao estado imediato das coisas, como se quem observa (a si mesmo ou ao que lhe é exterior) desconhecesse a passagem do tempo - e, portanto, não soubesse discriminar ou supor relações de causalidade.

Certo desprezo pelo tempo linear traz uma narrativa que adere completamente ao tempo presente, erigida numa ausência de passado e futuro ou na fusão de todos os tempos num só: o tempo do fato narrado. Isso aparecerá nas narrativas mais longas, e comparece, de forma mais radical, nos fragmentos da coletânea. Uma consciência imediata e fugaz faz sobressair em Contemplação a nítida impressão da instantaneidade, do presente contínuo que agrupa sobre si passado e futuro, como os dois homens que passam correndo diante do narrador sem que esse impeça as suas trajetórias, sem interessar de onde venham ou para onde vão. Tempo e espaço parecem dissolver-se em um caldo ácido misturando- 
LUGÃO, J. - O observador fotográfico em Contemplação

se homogeneamente às ações de seus personagens, tornando-as menores, de curta duração, fragmentadas, marginais, radicalmente contemporâneas. "Kafka não cedeu à sedução do mito", nos diz Walter Benjamin em seu ensaio sobre o autor (BENJAMIN 1994: 143). Nem ao tempo do mito, nem à liberdade: os fragmentos de Kafka enclausuram definitivamente narrador, personagens e leitor.

No entanto, essa economia, tanto estrutural e estilística (a forma breve) quanto de personagens, que não ganham profundidade subjetiva ou destinos épicos, traz justamente a potência e o interesse da narrativa Kafkiana. A mesma potência da imagem flagrante, do efeito paralisante de choque, da cena de um possível crime a ser denunciado na cidade vazia de Atget de que Benjamin fala em "Pequena História da Fotografia" (BENJAMIN 1994: 107).

Se contextualizar acontecimentos historicamente e narrá-los à exaustão como nos romances do século 19 eram práticas que começavam a ficar comprometidas a partir da proliferação sem precedentes de imagens fotográficas que o início do século 20 testemunhou, essas mesmas imagens podem ser o gatilho necessário para a manifestação consciente da efemeridade que assolava as vidas modernas e da velocidade das mudanças. “Caberia, portanto, à consciência demonstrar a provisoriedade de todas as configurações dadas, senão até mesmo de despertar o pressentimento de ordem justa do existente natural" (KRACAUER 2009: 79), escreve Kracauer em seu ensaio sobre a fotografia de 1927. É nesse ponto crucial do argumento de Kracauer que ele recorre justamente a Kafka, associando a narrativa do autor ao olhar fotográfico. Para ele, a escrita de Kafka - em geral, não especificamente em Contemplação - tanto ilustra como desafia esse processo:

Nas obras de Franz Kafka, a consciência emancipada assume essa obrigação; ela destroça a realidade natural e contrapõe os fragmentos um ao outro, mudando-lhes a ordem. Nada pode tornar mais evidente a desordem dos resíduos refletidos na fotografia que suprimir toda relação habitual entre os elementos naturais. (KRACAUER 2009: 79)

A escrita de Kafka, para Kracauer, portanto, leva esse efeito fragmentário, próprio da técnica fotográfica, ao extremo. Dissolvendo aquilo que é familiar da realidade, ela resiste à reintegração dos elementos a um todo harmonioso. A obra de Kafka mobilizaria a estética fotográfica da fragmentação sem oferecer espaço para a coerência ou a síntese.

Além disso, a prosa breve traz, a partir da delimitação do espaço da escrita, uma espécie de semelhança material com a fotografia, cujas bordas impõem o limite da porção 
LUGÃO, J. - O observador fotográfico em Contemplação

de realidade que a ser capturada. E Contemplação mostra ao leitor a vida da metrópole ${ }^{9}$, em que personagens e espaços permanecem anônimos, assim como a fotografia urbana, e para isso, o autor recorre a constantes mudanças de perspectiva, ângulos de visão Kafka fala, em carta a Felice, em „,kleine Winkelzüge“, pequenos truques, sem perder Winkel (ângulo) da palavra (KAFKA 2005: 438) ${ }^{10}$.

\section{Panorama Imperial}

Ao lado do fascínio pela fotografia, que pode ser visto nas descrições minuciosas das técnicas em seus diários, as Cartas a Felice sugerem que o autor seria bastante resistente a qualquer tentativa de estabelecer aproximações entre os retratos, que enviava à noiva, e sua escrita. Essas mesmas imagens são descartadas por Kafka, como distorcidas e enganosas, como na passagem: "Na realidade não faço caretas, tenho este olhar visionário apenas sob a luz de uma lâmpada de magnésio" "KAFKA 1985: 143). A escrita, por outro lado, é sempre objeto de maior vaidade e preocupação, ela sim seria capaz de representar o autor.

Entre todas as possibilidades oferecidas pelo advento e popularização da fotografia e da câmera portátil, chama a atenção o dispositivo do Panorama Imperial

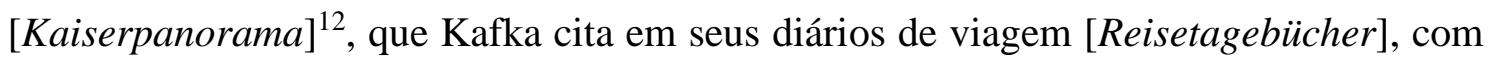
mais entusiasmo que o cinema e menos desconfiança que a fotografia. Ao descrever a experiência de visitar um equipamento desses em 1911, "sua única diversão em Friedland", Kafka reflete da seguinte forma sobre o dispositivo:

Kaiserpanorama. Única diversão em Friedland. Não me senti propriamente à vontade,

\footnotetext{
${ }^{9}$ Para Andreas Huyssen, Contemplação foi uma contribuição fundamental para a trajetória da literatura urbana em forma curta, "um experimento de escrita urbana que é conceitualmente ambicioso e literariamente ousado, de formas que transcendem as descrições miméticas das cenas urbanas que prevaleciam na Áustria". Cf. Miniature Metropolis: Literature in Age of Photography and Film, 2015.

${ }^{10}$ A tradução disponível em português usa a palavra "pretextos", que mantém o caráter de experimento, mas perde a semântica visual.

${ }^{11}$ „Ein verdrehtes Gesicht habe ich in Wirklichkeit nicht, den visionären Blick habe ich nur bei Blitzlicht“ (KAFKA 2005: 486). Verdrehtes Gesicht é mais que uma careta, como sugere a tradução, cara torta, ou rosto torto, remetendo, assim, a uma distorção da realidade e não a uma brincadeira. Kafka demonstra, aqui, assim como na carta em que envia três retratos à noiva, bastante desconforto diante da própria imagem. Um outro estudo poderia relacionar o desconforto com a própria imagem reproduzida e a insegurança que Franz Kafka vivia com sua escrita. Peter-André Alt, em biografia do autor, fala da sua dificuldade em escolher os fragmentos que integrariam Contemplação, por se questionar a todo o tempo (ALt 2005: 247).

${ }^{12}$ Mantenho a tradução que José Carlos Martins Barbosa utiliza para a mesma palavra em Infância em Berlim por volta de 1900, de Walter Benjamin, por se tratar, provavelmente, da expressão mais conhecida do leitor brasileiro. "Panorama do Kaiser" e "Panorama do Imperador" são outras denominações possíveis em português.
} 
LUGÃO, J. - O observador fotográfico em Contemplação

pois não esperava uma instalação tão bonita quanto a que encontrei; entrei com as botas sujas de neve e, assim, sentado diante do visor, mal encostava no carpete com as pontas dos pés. Tinha esquecido a disposição dos panoramas e, por um momento, tive medo de ter que ficar passando de uma cadeira para outra. Um velho em uma mesinha iluminada, lendo um exemplar de $O$ mundo ilustrado, dirigia tudo. Após algum tempo, um Ariston tocou para mim. Depois entraram também duas senhoras, sentam-se à minha direita, e depois outra, à esquerda. Bréscia, Cremona, Verona. Lá dentro pessoas parecidas com bonecos de cera, com as solas dos pés fincadas no chão da calçada. Monumentos fúnebres: uma mulher, com uma cauda que se arrastava por uma escadinha, entreabria uma porta enquanto olhava para trás. Uma família, tendo um jovem lendo em primeiro plano, com uma das mãos na têmpora, e um menino à direita, esticando um arco sem corda. Monumento do herói Tito Speri: desleixada e animadamente a roupa tremula sobre o corpo. Blusa, chapéu de aba larga. Imagens mais vivas do que no cinematógrafo, por darem ao olhar a calma da realidade. O cinematógrafo dá ao observado a agitação de seu movimento; a calma do olhar parece mais importante. Piso polido das catedrais diante de nossa língua. Por que não há uma união entre cinema e estereoscópio dessa forma? Cartazes com Pilsen Wihrer, conhecida de Bréscia. A distância entre a mera escuta de uma narrativa e a visão de um panorama é maior que a distância entre este último e a visão da realidade. Mercado de sucata em Cremona. No fim, tive vontade de dizer ao senhor idoso o quanto me fizera bem, não me atrevi. Recebi o próximo programa. Aberto das 10 às 10 horas (KAFKA apud SANTOS 2010: 26) ${ }^{13}$.

Diferente do fluxo contínuo de imagens que trazia o cinema, o Panorama Imperial ${ }^{14}$ possibilitava um equilíbrio entre movimento e estaticidade, entre o espetáculo e a contemplação. Conforme Hans Zischler, em seu estudo sobre as relações da obra de Kafka e o cinema, cada imagem do Panorama Imperial, exposta por cerca de dois minutos, poderia ser examinada em detalhe. Mais importante, cada imagem era separada pela exibição de slides vazios, uma intermitência que permitia reflexão, ponderação e imaginação e, "se havia um ponto arquimediano de rejeição da cinematografia, ele estava ali, em Friedland, no Kaiserpanorama”, escreve Zischler (ZISCHLER 2005: 40-42).

O que parece ser de maior importância para Kafka, no sentido de fazer do Panorama Imperial um meio superior ao cinema, era a possibilidade de interferência, reflexiva que fosse, do espectador. Enquanto a sequência de imagens do cinema é movimentada mecanicamente, são a imaginação e o olhar do espectador que criam a narrativa da sequência do Panorama Imperial. Para Carolin Duttlinger, as fotografias estereoscópicas e o episódio de Friedland, registrado nos diários, foram cruciais para o desenvolvimento da escrita de Kafka, pois desperta no autor um modo de percepção que pode mobilizar a ficção (DUTTLINGER 2007: 12).

\footnotetext{
${ }^{13}$ Recorro à tradução de Thiago Benites dos Santos (2010), em artigo que analisa a possível influência do Panorama Imperial sobre a escrita de Kafka, especialmente sobre "Uma mensagem imperial".

${ }^{14}$ Ao realizar viagens profissionais a Friedland e Reichenberg, Kafka aproveitou para, em momentos de descanso, se distrair com essa instalação, que já perdera espaço para o cinema e lhe era familiar desde a juventude em Praga. A partir da instalação, era possível assistir a uma sequência de fotografias estereoscópicas, que, através de um dispositivo binocular, surgiam aos olhos com efeito tridimensional.
} 


\section{"O Passageiro", narrativa breve de Contemplação}

Para, no ato de leitura, ser possível chegar ao mesmo efeito de repouso visual que Kafka admira no Kaiserpanorama, é preciso que se crie o movimento, a mudança de ângulos e o caminho do olhar. Os momentos de congelamento de imagem, de capturas do instantâneo (os lampejos) só serão de fato percebidos se o movimento for criado, para que o leitor, pela comparação de opostos, possa perceber movimento e fixidez. Neste ponto, Kafka, mais uma vez, joga com seu leitor. O tipo de leitura que os fragmentos de Contemplação demandam - em que é possível se deter numa palavra, numa passagem, numa imagem, voltar atrás e buscar coincidências - é uma experiência impossível para o espectador do cinema ou mesmo do Panorama Imperial, pois o dispositivo comanda o movimento de recepção, que é contínuo. O leitor acostumado a ter o controle sobre sua experiência é desafiado pelo texto de Kafka, que cria, com suas palavras, movimento e, para percebê-lo, é preciso se deixar levar pelo texto muitas vezes, deixar que o fluxo de texto ofereça os retornos e pausas.

Assim como a possibilidade de repouso do olhar parecem ter um privilégio sobre a experiência do cinema para Kafka, o autor mostra, sem recorrer a um manifesto em defesa da escrita, sendo os manifestos tão recorrentes em seu tempo, que a escrita ainda apresenta vantagens sobre a imagem fotográfica, sem no entanto, deixar de inscrever na escrita a dimensão visual característica da fotografia (e não da pintura, por exemplo).

Como vimos, quando descreve Contemplação para Felice, Kafka usa a palavra Lichtblick (lampejo), palavra que implica uma conotação de imagens repentinas, fazendo lembrar o flash fotográfico (Blitzlicht). Um bom exemplo da tensão entre Lichtblick e Blitzlicht em Contemplação se encontra no parágrafo central de O Passageiro, fragmento que se encontra, não surpreendentemente, no centro do livro. O instantâneo descrito a seguir, é justaposto ao bonde em movimento.

Primeiramente, Kafka apresenta ao leitor o ângulo da fotografia - e do fotógrafo: "Estou em pé na plataforma do bonde e totalmente inseguro em relação à minha posição neste mundo, nesta cidade, na minha família” (KAFKA 1999: 28). Trata-se, então, de um narrador-personagem-fotógrafo, que é um mero passageiro no típico espaço da metrópole, a plataforma do bonde, um anônimo entre tantos - assim como os fotógrafos, que não raro sequer sabemos quem são. No segundo parágrafo o narrador-fotógrafo faz uma descrição detalhada da mulher que lhe está perto. O leitor tem diante de si um olhar 
LUGÃO, J. - O observador fotográfico em Contemplação

que sugere um enquadramento próximo, sem tirar o anonimato da transeunte - outra característica da fotografia, capaz, com suas lentes teleobjetivas, de capturar certa intimidade do indivíduo fotografado sem interferir nas suas práticas. A passagem também é, notavelmente, livre de qualquer interferência de possíveis visões periféricas, do que se passa à volta, ou mesmo uma descrição do movimento do bonde, mais uma vez sugerindo o enquadramento fechado:

Aparece tão nítida para mim que é como se eu a tivesse apalpado. Está vestida de preto, as pregas da saia quase não se movem, a blusa é justa e tem uma gola de renda branca fina, ela mantém a mão esquerda espalmada na parede do bonde e sombrinha da mão direita se apóia no penúltimo degrau mais alto. Seu rosto é moreno, o nariz levemente amassado dos lados termina redondo e largo. Tem cabelos castanhos fartos e pelinhos esvoaçando na têmpora direita. Sua orelha pequena é bem ajustada, mas por estar próximo eu vejo toda a parte de trás da concha direita e a sombra da base (KAFKA 1999: 28-29).

A leitura desse trecho poderia até confirmar a frase de Kracauer, em seu ensaio sobre a fotografia, segundo a qual é a moda, em seus detalhes, que atrai e mantém fixo o olhar - chamando a atenção para a dimensão concreta da busca visual (KRACAUER 2009: 72).

Na passagem, não há troca de olhares entre o narrador e a mulher vestida de preto. É o olhar do narrador (como se fosse a lente mecânica da câmera) que registra, de modo estereoscópico, com precisão tátil, a vestimenta da moça. A ausência de distrações nesse enquadramento, que até poderia surgir no movimento do bonde, marca a relação do ângulo fechado da câmera com um olhar completamente concentrado. Diferentemente da descrição realista tradicional, essa passagem não apresenta nenhum contexto. O encontro casual de um passageiro anônimo com uma mulher de quem nada sabemos (o narrador abdica da posição onisciente e não nos dá qualquer pista para compreender o significado a roupa preta, foco de atenção do passageiro) e a percepção detalhada produz uma sensação de estranhamento no leitor, que não assistirá ao surgimento uma paixão à primeira vista, nem saberá por que a moça está de preto. Assim como uma fotografia urbana anônima, congelou-se uma imagem no tempo.

O próprio narrador-fotógrafo reflete, assim, sobre a imagem que viu, garantindo o repouso e a reflexão reivindicados por Kafka. Se, no início do fragmento, a mulher parecia uma antítese firme e segura à insegurança do narrador tal como se apresenta no primeiro parágrafo, terminamos com as reflexões sobre a imagem do narrador-fotógrafo: "Naquela ocasião eu me perguntei: como é que ela não está espantada consigo mesma, conserva a boca fechada e não diz coisas desse tipo?” (KAFKA 1999: 29). 
LUGÃO, J. - O observador fotográfico em Contemplação

A mulher, aqui, é apenas o objeto da foto, a ela não se dá as nuances de uma personagem. Embora o olhar sobre a mulher seja uma imagem congelada, é preciso lembrar que tudo ocorre num bonde em movimento, se aproximando da parada onde ela deixará o veículo. O movimento e o congelamento da imagem precisam, aqui, ser justapostos para que o leitor possa perceber o momento de paralização do movimento. Kafka faz, assim, com que a escrita literária, ainda que permeada, contaminada pelas novas formas de percepção e representação, apareça como a mais potente entre elas. A escrita literária permite, aqui, a escolha do ângulo de visão, a justaposição entre movimento e congelamento e o tempo de reflexão.

\section{Considerações Finais: oálbum à kafkiana}

Em carta de 17 de Dezembro de 1934 endereçada a Walter Benjamin, Adorno descreve a obra de Kafka como a de um fotógrafo mundano que usa uma câmera imaginária para gravar cenas da modernidade, a partir de uma perspectiva redentora, que salva os instantes que passam (ADORNo 2012: 127). Carolin Duttlinger (2007: 259) chama a atenção para outra possibilidade de interpretação da obra do autor, também incluindo a fotografia: embora Kafka não utilize uma câmera como instrumento para sua expressão - era, afinal, escritor e não fotógrafo - seus textos são, de fato, capazes de apresentar ao leitor, por meio da palavra, a posição do fotógrafo, seus ângulos e enquadramentos, justamente porque ele não pretendia corrigir os limites da fotografia. Enquadramento, posição do fotógrafo, momento do flagrante não são corrigidos na escrita, mas aproveitados por ela.

Se a escrita literária é, em Kafka, mais potente do que a fotografia naquele momento, isso se deve à capacidade do autor de perceber os limites dessa linguagem visual e se utilizar deles como formas de potencializar a escrita. O olhar a partir de um ângulo único (ou apenas uma voz narrativa), a ênfase (o foco) em detalhes aparentemente menos importantes, ou, ainda, as descrições detalhadas, parecem prometer uma narrativa realista (a história de amor entre o passageiro e a moça vestida de preto, de quem ele não consegue desviar o olhar) ou outros significados mais profundos. A escrita de Kafka em Contemplação resiste a esse desenvolvimento e mantém as imagens fixas, opacas - a partir das imagens criadas pelas palavras, o leitor pode exercitar o olhar, pois o texto oferece uma sequência de imagens.

Mais do que buscar significados para a fotografia em seu tempo, ou ensaiar críticas

Pandaemonium, São Paulo, v. 24, n. 44, set.-dez. 2021, p. 141-156 
LUGÃO, J. - O observador fotográfico em Contemplação

a ela, os textos de Kafka reforçam seu caráter misterioso, assustador e opaco - é impossível determinar, com clareza, quem está por trás da lente (ou da pena), por que aquele ângulo foi escolhido, por que determinado foco e não outro. A atração de Kafka pela fotografia parece voltar-se justamente para os aspectos que fazem essa forma de representação visual encontrar (ou demandar) a literatura, mas ele não ultrapassa essa fronteira. É como se o que houvesse de mais interessante na fotografia fosse justamente o limite em representar a realidade e esse limite pudesse ser recriado, sublinhado na escrita. A fotografia, em algum momento, demanda a palavra escrita e Kafka, em vez de responder preenchendo lacunas, incorpora essa insegurança ao texto literário, tanto mais potente quanto devedor dessa nova técnica e forma de percepção.

Há, em Contemplação, uma relação da escrita mediada pela visualidade, pela fotografia, que, como Andreas Huyssen argumenta (2015), conecta esse livro aos escritos de Walter Benjamin e Siegfried Kracauer, duas décadas mais tarde. ${ }^{i}$ A fotografia ou cinema não são mencionados explicitamente em Contemplação: é uma estrutura visual subjacente à escrita, uma ausência que ressalta ainda mais o impacto desses novos meios de representação sobre a escrita do autor.

Assim como Walter Benjamin e Siegfried Kracauer, Kafka não permite que a chegada da fotografia e sua incontornável incorporação às práticas cotidianas visuais, passem despercebidas de suas críticas e criações literárias - mas não unicamente pela via do comentário, e sim pela absorção de aspectos da técnica em suas práticas. A partir de Kafka, a ideia de uma imagem num texto literário não pode mais ser pensada como metáfora ou descrição ecfrástica somente, pois deve contemplar as transformações trazidas pelos novos meios técnicos.

Com Contemplação o autor cria um álbum literário à maneira de um álbum de fotografias. Assim como em um álbum de fotografias, não há, em Contemplação, um fio narrativo. Nos álbuns, percebemos os espaços entre as imagens, as lacunas, há tempo para o repouso do olhar e o trabalho da imaginação. Mas álbuns fotográficos remetem a um passado com suas imagens. E o álbum formado em Contemplação mostra ao leitor lampejos do que estaria por vir em sua escrita.

No álbum de fotografias, a imagem é congelada, traz um passado, atravessa o tempo, é talvez eternizada. Em Contemplação, o presente de cada fragmento, sem passado ou futuro, dura uma eternidade. 


\section{Referências bibliográficas}

Adorno, Theodor; Benjamin, Walter. Correspondência 1928-1940 Adorno-Benjamin. Trad. José Marcos Mariani de Macedo. São Paulo: Unesp, 2012.

Alt, Peter-André. Franz Kafka: Der ewige Sohn. Eine Biographie. München: CH Beck, 2005.

BENJAMIN, Walter. A pequena história da fotografia. In: BENJAMIN, Walter. Obras escolhidas I - Magia, técnica, arte, política. Trad. Sergio Paulo Rouanet. São Paulo: Brasiliense, 1994, 91-107.

Benjamin, Walter. Franz Kafka. A propósito do décimo aniversário de sua morte. In: BeNJAMIN, Walter. Obras escolhidas I - Magia, técnica, arte, política. Trad. Sergio Paulo Rouanet. São Paulo: Brasiliense, 1994, 137-164.

BENJAMIN, Walter. O Surrealismo - o último instantâneo da inteligência europeia. In: BENJAMIN, Walter. Obras escolhidas I-Magia, técnica, arte, política. Trad. Sergio Paulo Rouanet. São Paulo: Brasiliense, 1994, 21-35.

BruHn, Mathias. Das Bild: Theorie, Geschichte, Praxis. Berlin: Akademie Verlag, 2008.

DutTlinger, Carolin. Kafka and Photography. New York: Oxford University Press, 2007.

HUYSSEN, Andreas. Kafka's Betrachtung in the Force Field of Photography and Film. In: HUYSSEN, Andreas. Miniature Metropolis: Literature in Age of Photography and Film. Harvard University Press: Cambridge; London, 2015, 52-83.

KAFKA, Franz. A metamorfose. Trad. Modesto Carone. São Paulo: Companhia das Letras, 1997.

KAFKA, Franz. Cartas a Felice. Trad. Robson Soares de Medeiros. Rio de Janeiro: Anima, 1985.

KAFKA, Franz. Contemplação/ O foguista. Trad. Modesto Carone. São Paulo: Companhia das Letras, 1999.

KAFKA, Franz. Die Briefe. Frankfurt a.M.: Zweitausendeins, 2005.

KraCAUER, Siegfried. A fotografia. In: KraCAUER, Siegfried. O Ornamento da massa. Trad. Carlos Eduardo Jordão Machado. São Paulo: Cosac Naify, 2009, 63-80.

NeYMEYR, Barbara. Betrachtung, In: Aueroch, Bernd; ENGEL, Manfred. (orgs). KafkaHandbuch. Stuttgart: JB Metzler, 2010, 111-126.

RICHTER, Gerhard. Unsettling Photography: Kafka, Derrida, Moses. CR - The New Centennial Review, Remainders: Of Jacques Derrida (fall 2007), Michigan State University Press, v. 7, n. 2, 155-173, 2007.

SANTOS, Thiago Benites dos. Franz Kafka e o medium Kaiserpanorama. Revista Contingentia, v. 5, n. 2, 23-32, 2010.

SCHÖTTKER, Detlev. Vielfältiges Sehen - Franz Kafka und der Kubismus in Prag. Zeitschrift für Ideengeschichte, Heft IV (4), 85-98, 2010. Online: http://www.z-i-g.de/ (05/07/2017).

ZISCHLER, Hanns. Kafka vai ao cinema. Trad. Vera Ribeiro. Rio de Janeiro: Jorge Zahar Editor, 2005. 